'Departamento de Imágenes, Clínica Alemana de Santiago ${ }^{2}$ Centro de Imagenología Hospital Clínico de la Universidad de Chile.

${ }^{a}$ Médico Becado de Radiología,

Facultad de Medicina Clínica Alemana-Universidad de Desarrollo, Hospital Padre Hurtado.

Recibido el 6 de abril de 2009, aceptado el 28 de enero de 2010

Correspondencia a: Dr. Claudio Cortés A. Departamento de Imágenes, Clínica Alemana de Santiago Vitacura 5951, Vitacura, Santiago, Chile. Fono: 56-2- 2101111 Fax: 56-2-210 1214 E-mail: claudiocort@gmail.com

\section{Cuerpos extraños en la vía aérea: Uno a cada lado en forma simultánea. Caso clínico}

\author{
CLAUDIO CORTÉS A. ${ }^{1,2}$, BENJAMÍN HORWITZ Z. a, JUAN CARLOS DÍAZ ${ }^{1,2}$
}

Inhaled foreign bodies can be a life-threatening emergency and requires immediate intervention. We report a 40-year-old man who came to the ER complaining of chest pain and cough. He had lost his dental prosthesis. Chest X-Rays showed two foreign bodies, one at the intermediate bronchus and the other at the left posterior basal segmental bronchus. By fibrobronchoscopy, porcelain fused to a metal dental crown of six teeth was extracted from the right side, and a cast of metal from the left side.

(Rev Med Chile 2010; 138: 470-472).

Key words: Airway obstruction; Dental prosthesis; Foreign bodies.

L os cuerpos extraños inhalados pueden convertirse en una emergencia que pone en riesgo la vida de los pacientes, y que requieren intervención inmediata ${ }^{1}$. Sin embargo, en algunos casos los síntomas pueden pasar desapercibidos por años, causando graves secuelas. Por esto es muy importante hacer un diagnóstico oportuno, ya que ello se correlaciona con mayor facilidad en la extracción debido a que la persistencia del cuerpo extraño en la vía aérea es capaz de provocar una reacción inflamatoria secundaria que puede hacer imposible su manejo endoscópico. La radiografía de tórax es el método más eficiente para estos propósitos. La extracción de estos cuerpos extraños lleva a una rápida recuperación de los síntomas².

\section{Caso clínico}

Un paciente de sexo masculino de 40 años de edad que consultó durante la madrugada en el Servicio de Urgencias quejándose de dolor toráxico y tos. El paciente relataba la sospecha haber aspirado su prótesis dentaria.

La radiografía de tórax en proyecciones poste- ro-anterior (Figura 1) y lateral (Figura 2) demostró la presencia de dos cuerpos extraños en la vía aérea, uno alojado en el bronquio intermediario y el otro en el bronquio para el segmento basal posterior izquierdo. Se decidió realizar fibrobroncoscopia flexible, donde se visualizó la presencia de una

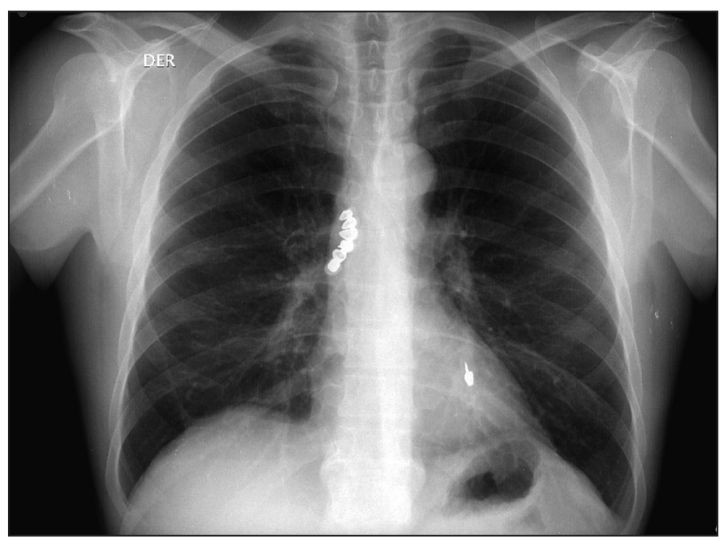

Figura 1. Radiografía de Tórax PA: Cuerpos extraños radioopacos, uno visible en la región para-mediastínica derecha (sobreproyectado al bronquio intermediario derecho), y otro sobreproyectado a la región del corazón. 


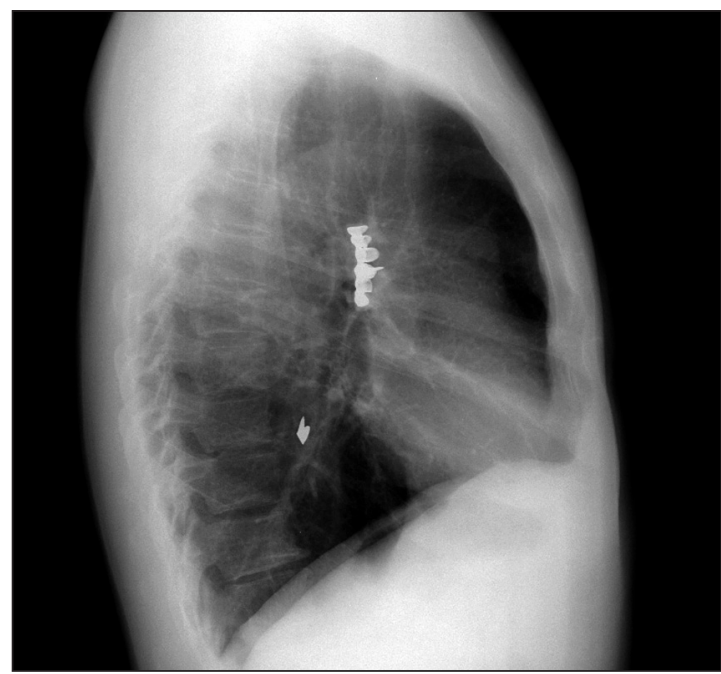

Figura 2. Radiografía de Tórax Lateral: Se confirma la presencia de los cuerpos extraños observados en la proyección PA, y la sobreproyección en el bronquio intermediario derecho y en un bronquio segmentario izquierdo.

prótesis con seis coronas dentarias de porcelana fusionadas con metal desde el lado derecho, y un molde de metal en el izquierdo (Figura 3). Ambas fueron extraídas en forma satisfactoria y sin complicaciones inmediatas ni tardías.

\section{Discusión}

La presentación clínica de los cuerpos extraños en vía aérea muchas veces no es específica, y la radiografía de tórax resulta muy útil y eficaz para la identificación y localización de los cuerpos extraños cuando son radioopacos o incluyen elementos metálicos. Es una patología frecuente en la población infantil, que no da datos anamnésticos y concurren por prolongados períodos de tos o cuadros neumónicos que repiten igual localización. También se presentan con fenómenos atelectásicos o con hiperinsuflaciones parenquimatosas segmentarias por fenómeno de válvula, ya que el aire sobrepasa la zona estrecha en la inspiración y queda atrapado en la espiración. Cuando no se detectan y tratan en forma oportuna pueden producir complicaciones como bronquiectasias, neumonías necrotizantes y pérdidas importantes del parénquima pulmonar.

La extracción pude realizarse posteriormente

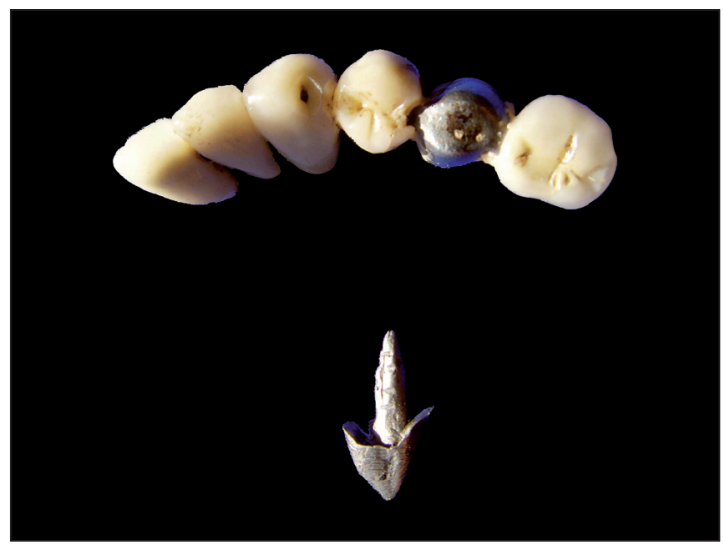

Figura 3. Fotografía de los cuerpos extraños extraídos mediante fibrobroncoscopia: Arriba: La prótesis dentaria de 6 piezas de porcelana fusionada con metal extraída desde el bronquio intermediario derecho. Abajo: Molde metálico obtenido desde el bronquio para el segmento basal posterior izquierdo.

en forma dirigida con el uso de broncoscopios rígidos o flexibles, catéter con balón de Fogarty, o canastillos alambrados ${ }^{3-5}$.

Otros autores han comunicado casos similares $^{6}, y$ también muestran buenos resultados diagnósticos a través del uso de radiografía de tórax en dos proyecciones, y terapéuticos con extracción oportuna del cuerpo extraño y sin complicaciones.

El caso de nuestro paciente resulta más inusual, ya que presentaba 2 cuerpos extraños en bronquios contralaterales, lo que le otorga además un factor de mayor peligrosidad. La mayoría de las veces, los cuerpos extraños aspirados por pacientes adultos se dirigen a través del bronquio derecho debido a su orientación más vertical respecto del izquierdo ${ }^{7}$.

La gran mayoría de los cuerpos extraños en la vía aérea son extraídos con el uso de métodos endoscópicos, y sólo en casos muy raros es necesario acudir a la toracotomía o broncotomía para removerlos.

\section{Referencias}

1. Baharloo F, Veyckemans F, Francis C, Biettlot MP, Rodenstein DO. Tracheobronchial foreign bodies: presentation and management in children and adults. Chest 1999; 115: 1357-62. 
2. Al-Majed SA, Ashour M, al-Mobeireek AF, al-Hajjaj MS, Alzeer $\mathrm{AH}$, al-Kattan K. Overlooked inhaled foreign bodies: late sequelae and the likelihood of recovery. Respir Med 1997; 91: 293-6.

3. Bossert T, Gummert JF, Barten M, Garbade J, Vogtmann M, Mohr FW. Foreign body in the airway: unusual cause of acute dyspnoe after cardiac surgery. Z Kardiologie 2005; 94: 375-6.

4. Tariq SM, George J. Images in clinical medicine. Inhaled foreign body. N Engl J Med 2004; 351: e8.
5. Zarrin-Khameh N, Lyon RE. Images in clinical medicine. Asphyxia due to an inhaled foreign body. N Engl J Med 2005; 352: 2110.

6. Peters TE, Racey GL, Nahman BJ. Dental prosthesis as an unsuspected foreign body. Ann Emerg Med 1984; 13: 60-2.

7. Sakellaridis T, Koulaxouzidis G, Panagiotou I, Kigka C, Papamichalis G, Antypas G. Aspiration of fixed dental prosthesis following maxillofacial trauma. Emerg Med J 2008; 25: 143 . 